\title{
Educação e ancestralidade em Lima Barreto: um narrador em busca da reconciliação com o passado
}

\author{
Educación y ancestralidad en Lima Barreto: un narrador en busca de la \\ reconciliación con el pasado
Education and ancestrality in Lima Barreto: a narrator in search of reconciliation with the past

\author{
Carlos Eduardo Gomes Nascimento ${ }^{1}$
}

\begin{abstract}
Resumo
Trata-se de uma discussão sobre a narrativa do escritor negro Lima Barreto sobre o tema da ancestralidade da cultura afro-brasileira e sua importância na educação dos jovens. Lima Barreto foi um autor crítico das instituições políticas, sociais e econômicas da Primeira República no Brasil, no período do início do século XX. Através da literatura, romances, contos e crônicas, Lima Barreto retratou uma população de excluídos sociais: os negros, os pobres, as mulheres negras, os loucos etc. O presente artigo objetiva apresentar um recorte da obra de Lima Barreto, expondo como sua narrativa literária reivindica por uma ancestralidade da população afrodescendente. A partir do ponto de vista crítico de Lima Barreto, analisa-se: o contexto histórico das teorias raciais em voga no Brasil do início do século XX e a importância de defender a ideia de ancestralidade enquanto uma forma de resistência nas narrativas, na cultura e na religiosidade que são transmitidas de uma geração mais antiga para uma nova geração. A partir dessas reflexões, o texto propõe um diálogo entre o conhecimento da ancestralidade apresentado nas narrativas de Lima Barreto e uma possível conscientização da formação da sociedade brasileira aos jovens estudantes.
\end{abstract}

Palavras-chave: Ancestralidade; Educação; Racismo; Lima Barreto.

\section{Resumen}

Se trata de una discusión sobre la narrativa del escritor negro Lima Barreto sobre el tema de la ancestralidad de la cultura afro-brasileña y su importancia en la educación de los jóvenes. Lima Barreto fue un autor crítico de las instituciones políticas, sociales y económicas de la Primera República en Brasil, en el período de principios del siglo XX. A través de la literatura, romances, cuentos y crónicas, Lima Barreto retrató una población de excluidos sociales: los negros, los pobres, las mujeres negras, los locos, etc. El presente artículo tiene como objetivo presentar un recorte de la obra de Lima Barreto, exponiendo como su narrativa literaria reivindica por una ancestralidad de la población afrodescendiente. A partir del punto de vista crítico de Lima Barreto, se analiza: el contexto histórico de las teorías raciales en boga en Brasil de principios del siglo XX; la importancia de defender la idea de ancestralidad como una forma de resistencia en las narrativas, la cultura y la religiosidad que se transmiten de una generación más antigua a una nueva generación. A partir de esas reflexiones, el texto propone un diálogo entre el conocimiento de la ancestralidad presentado en las narrativas de Lima Barreto y una posible concientización de la formación de la sociedad brasileña a los jóvenes estudiantes.

Palabras clave: Ancestralidad; la educación; racismo; Lima Barreto

\footnotetext{
${ }^{1}$ Mestre em Educação e Graduada em Licenciatura em Filosofia; professor da rede pública do Estado da Bahia; Salvador, Bahia, Brasil; carlos_gomes02@ hotmail.com.
} 


\begin{abstract}
It's a discussion about the narrative of the black writer Lima Barreto on the theme of the ancestry of AfroBrazilian culture and its importance in the education of the young. Lima Barreto was a critical author of the political, social, and economic institutions of the First Republic in Brazil in the early XX. Through literature, novels, short stories and chronicles, Lima Barreto portrayed a population of socially excluded: the blacks, the poor, the black women, the crazy, etc. This article aims to present a cut of the work of Lima Barreto, exposing how his literary narrative claims for ancestral Afrodescendant population. From the critical point of view of Lima Barreto, we analyze: the historical context of the racial theories in vogue in Brazil in the early twentieth century; the importance of defending the idea of ancestry as a form of resistance in the narratives, culture and religiosity that are transmitted from an older generation to a new generation. Based on these reflections, the text proposes to include in education the dialogue between the knowledge of ancestry presented in the narratives of Lima Barreto and a possible awareness of the formation of Brazilian society to young students.
\end{abstract}

Keywords: Ancestrality; Education; Racism; Lima Barreto.

\title{
1. Reavivar histórias
}

"Tinha penetrado no passado, no passado vivo, na tradição"

(BARRETO, 1919, p.108)

Dona Felismina, uma mulher negra brasileira, entre muitas, que luta para criar seu filho sozinha, lavando a roupa de outras pessoas. Uma mãe que tinha o desejo de oferecer a seu filho Zeca uma educação que pudesse proporcionar ao pequeno garoto uma vida diferente. D. Felismina sabia da importância das letras e sentia isso todas as vezes que arrumava Zeca para a escola. Ela havia conseguido com uma de suas patroas uma bolsa de estudos para Zeca em um colégio particular. Zeca, único jovem negro da escola, sabia do esforço de sua mãe, que, depois de um dia exaustivo no trabalho, mesmo sem compreender bem o conteúdo, dedicava-se em ajudá-lo com as lições. Mesmo diante das dificuldades, quando a escola solicitava um material diferente, D. Felismina sempre encontrava uma maneira de o conseguir para o filho. O preconceito racial e social ressaltava-se na presença de Zeca na escola entre os colegas que, certa vez, o chamaram de negro, de moleque. A escola fez vistas grossas àquela situação. D. Felismina notou que Zeca tinha na mochila algo diferente. Zeca relutou em abrir a mochila, mas por respeito à mãe abriu. Era uma máscara negra que tinha chifres recurvados, olhos proeminentes e uma bocarra. D. Felismina assustou-se diante de tanto horror. Perguntou ao filho onde havia conseguido. Zeca respondeu que o senhor Barreto, o vizinho, um preto velho, após ouvir a história dos garotos na escola, havia lhe dado a máscara sem que lhe pedisse. Senhor Barreto disse que ele mesmo tinha feito aquela máscara, era uma tradição antiga da família dele, que havia vindo do outro lado do oceano, da África. A mãe então 
perguntou ao filho: - Para que você está levando a máscara para a escola? — Para meter medo nos garotos que me chamaram de moleque.

Reavivar o passado para compreender o presente. Essa é uma releitura da história de dona Felismina e Zeca, personagens de Lima Barreto, no conto "O moleque", publicado no início do século XX. Uma história cotidianamente vivenciada no Brasil por milhares de mulheres negras que lutam para criar seus filhos.

Durante a formação da sociedade brasileira houve muitas formas de violência sofrida pela população negra escravizada. Esse tipo de violência estampava-se no corpo de mulheres, homens e crianças negros. Eram formas de violências não apenas infligidas na carne, mas também na alma. Negros eram punidos à chicotada no pelourinho, mulheres negras eram violentadas pelos senhores, manifestações de religiosidade africana eram proibidas. Essas são marcas que ainda perduram no Brasil: com o assassinato de jovens negros nas periferias, a exploração do corpo da mulher negra enquanto objeto do turismo sexual, o racismo contra religiões de matriz africana.

Em busca do passado, de uma tradição negra e brasileira suprimida, para compreender o presente, Lima Barreto, escritor carioca negro do início do século $\mathrm{XX}$, toma como sua matéria bruta a vida de pessoas marginalizadas, sobretudo os afrodescendentes. A literatura enquanto mobilização política e ideológica dos marginalizados busca reavivar o passado, trazer a memória dos antepassados às novas gerações. A arte literária de Lima Barreto causou estranheza, à sua época, para Francisco de Assis Barbosa (2002, p. 259):

Literatura não era escrever bonito. Não era instrumento de prazer para os ricos. Não era, em suma, o "sorriso da sociedade", como a definirá mais tarde Afrânio Peixoto. Assim como se rebelava contra essa deturpação da missão do escritor, não podia ele admitir a literatura contemplativa, a literatura plástica, a literatura apenas pela literatura.

Os personagens de Barreto vivenciavam o sacrifício dos trabalhos mais duros, em meio à fome; expulsos dos centros urbanos, viviam nos subúrbios em pequenos casebres, vítimas do preconceito e da discriminação racial e social, por vezes institucionalizada: alguns foram recolhidos em sanatórios, sob a alegação de loucura. Conforme Lilia Moritz Schwarcz (2017, p. 10), “os protagonistas variavam nos tons expressos na cor da pele, e moravam em locais mais distantes do centro da cidade, que ressoavam um passado africano. Uma África afetiva e pessoal, da margem de cá, um continente imaginado e recriado no país”. Essa matéria da marginalização social histórica na cor da pele negra constituiu a maior parte das imagens da ficção de Lima Barreto. 
Afonso Henriques de Lima Barreto — segundo filho de Amália Augusta, professora, e João Henriques, que trabalhava como tipógrafo da Imprensa Nacional —, neto de escravos, nasceu no Rio de Janeiro em 13 de maio de 1881, data em que sete anos mais tarde seria abolida a escravatura no Brasil através da Lei Áurea. Afonso Henriques e seus irmãos Carlindo, o mais velho, Evangelina e Eliézer tornaram-se órfãos ainda muitos jovens. Amália Augusta morreu de tuberculose. Ao assumir o cuidado dos filhos, João Henriques demitiu-se do cargo de tipógrafo para aceitar uma proposta de trabalho como administrador da Colônia de Alienados na ilha do Governador. A loucura e a marginalização social começaram a fazer parte desde cedo da vida cotidiana do garoto.

O jovem Afonso Henriques retornou à cidade do Rio para estudar, seu pai tinha o sonho de ver o filho tornar-se doutor. Foi o único jovem negro tanto no secundário, no Colégio Dom Pedro II, quanto na Politécnica do Rio, onde abandonou o curso de engenharia civil. Insatisfeito com a hipocrisia social e o constante preconceito racial, dedicou-se à literatura, ao jornalismo e à filosofia, como formas de resistir e de denunciar o racismo. Naquele momento, seu pai fora diagnosticado com loucura. Os papéis inverteram-se e a loucura voltou a rondar a vida de Afonso Henriques Lima Barreto. A fim de cuidar do pai e dos irmãos, o jovem escritor negro assumiu o cargo de amanuense na Secretaria da Guerra, onde se tornou um crítico, por meio de seus textos literários e jornalísticos, das estruturas institucionais da Primeira República regida pela troca de favores, excesso de burocracia e, principalmente, do preconceito racial.

Frente a uma sucessão de infortúnios, a literatura constituiu-se como expressão e paixão para Lima Barreto. O seu primeiro romance, Recordações do Escrivão Isaías Caminha (1997), publicado em 1909, conta a história de Isaías Caminha, um jovem negro ainda muito ingênuo que, antes de ir para a capital, acreditava que se tornar doutor poderia mudar a situação social frente à cor de sua pele. Assim relembra Isaías Caminha: “Ah! Seria doutor! Resgataria o pecado original do meu nascimento humilde, amaciaria o suplício premente, cruciante e onímodo de minha cor [...]" (BARRETO, 1997, p. 45).

Naquele momento histórico, a ciência erigida como o principal saber humano enunciava verdades. O determinismo científico de Hippolyte Taine, Arthur de Gobineau, Cesare Lombroso e Herbert Spencer construiu um conceito de raça associado à criminalidade, à loucura e à incapacidade intelectual. Tal pensamento foi recepcionado no Brasil por médicos e pensadores como Nina Rodrigues, Silvio Romero e Euclides da Cunha, entre outros. Os afrodescendentes, negros e mestiços, começaram a ser diagnosticados como predispostos à criminalidade e a doenças como demência, tuberculose e epilepsia. Esse fator 
científico constituiu forte ingerência sobre a vida cotidiana brasileira. Lima Barreto, através da literatura, foi um dos primeiros a se insurgir contra essa forma de discriminação das teorias raciais. Em um trecho de 1903, em seu Diário Íntimo, o autor negro escreveu: "o que define uma ciência não é o objeto que ela considera, é o ponto de vista em que ela o considera" (BARRETO, 1956, p. 23).

\section{Lima Barreto contra teorias raciais}

Ao longo da história do Brasil, a cor da pele constituiu-se um demarcador social, mesmo com o fim do regime escravocrata. Mas, durante a Primeira República, período em que Lima Barreto viveu, consolidou-se um discurso que se constituiria como uma verdade para a manutenção daquela estrutura de poder. Institucionalizado pelo Estado brasileiro, o discurso das teorias raciais fundamentava-se no conhecimento científico da época, cujo objetivo era justificar o racismo contra brasileiros negros e descendentes de pessoas escravizadas.

O pensamento positivista proposto pelo francês Augusto Comte, no século XIX, estabeleceu-se como principal fundamento ideológico do poder na Primeira República e constituiu-se enquanto um projeto político e social. Para os positivistas brasileiros, em sua maioria militares republicanos, o conhecimento científico definiria de maneira determinante e utilitarista uma condução para o progresso da sociedade brasileira.

Lima Barreto tornou-se um crítico dessa ideologia positivista, amplamente difundida no espírito da elite detentora do poder na sociedade brasileira. Em seu romance mais conhecido, Triste Fim de Policarpo Quaresma (2011), Lima Barreto avalia como o positivismo apossou-se do Estado brasileiro, em nome do progresso, cometendo violências contra o povo e contra a história do Brasil. Conforme Barreto (2010, p. 135):

Eram os adeptos desse nefasto e hipócrita positivismo, um pedantismo tirânico, limitado e estreito, que justificava todas as violências, todos os assassínios, todas as ferocidades em nome da manutenção da ordem, condição necessária, lá diz ele, ao progresso e também ao advento do regime normal, a religião da humanidade.

A apropriação nacional dos discursos dos cientistas e pensadores europeus manteve o preconceito contra os saberes tradicionais da cultura brasileira como uma estrutura de poder. Com a valorização do saber científico associado ao poder dito pelo olhar e pela boca do estrangeiro, criou-se uma espécie de casa de espelhos, em que grande parte dos brasileiros não 
se reconheciam. Em oposição a essa perspectiva, o personagem Policarpo Quaresma representa de modo singular uma defesa da cultura e da identidade nacional contra os estrangeirismos no Brasil. Entre os infortúnios de Quaresma, em sua cruzada pelo resgate das tradições brasileiras, o Estado responde com a internação do herói do Brasil no hospício.

No mesmo ano de publicação de Triste Fim de Policarpo Quaresma, no Congresso Universal de Raças ocorrido em Londres em 1911, o médico e antropólogo João Batista de Lacerda defendeu no seu artigo "The Metis, or half-breeds, of Brazil" ("Os mestiços do Brasil”) soluções para o problema das relações inter-raciais no Brasil. Escreveu Lacerda:

O casamento entre mestiços e brancos não são mais desprezados como anteriormente, agora que a posição elevada do mulato é a prova de suas qualidades morais, o que tem levado as pessoas a ignorar o contraste evidente de suas características físicas, e sua origem negra é perdida de vista na aproximação das suas qualidades morais e intelectuais aos do branco. $\mathrm{O}$ próprio mulato se esforça, por casamento, para trazer de volta seus descendentes para o tipo branco puro. A seleção sexual tende a neutralizar a do atavismo e remove dos descendentes todos os traços característicos da raça negra. Em virtude deste processo de redução étnica, é lógico esperar que, no curso de mais um século, os mestiços terão desaparecido do Brasil. Isto irá coincidir com a extinção paralela da raça negra em nosso meio (LACERDA, 1911, p. 382).

Nas palavras de Lacerda, as comunidades científicas da Europa e dos EUA não deveriam ficar preocupadas, pois o Brasil estava iniciando um processo de eugenia racial, o branqueamento das raças. O objetivo era pôr um fim ao atavismo da miscigenação racial que trazia características comportamentais, psicológicas e biológicas de raças consideradas inferiores, como a negra e a indígena, com a perspectiva de extinguir a cultura afrodescendente.

Desde fins do século XIX, constituiu-se uma teoria da degeneração racial desenvolvida em diversas pesquisas científicas no Brasil, principalmente na Escola Tropicalista Baiana, formada por um grupo de médicos brasileiros dedicados a descobrir as causas das doenças tropicais entre a população negra e miscigenada. Um dos seus principais representantes foi o médico maranhense Nina Rodrigues (1862-1906), que buscou demonstrar a teoria da degeneração racial no Brasil causada pela mestiçagem. Ao tomar os argumentos das teorias raciais europeias, Nina Rodrigues afirmava que o fenótipo mestiço possuía a predisposição para a criminalidade e para a loucura. Em seu artigo "Mestiçagem, degenerescência e crime" (1899), Rodrigues produz diagnósticos sobre a população do sertão baiano:

A população de Serrinha é composta de mestiços. O tipo pardo, que reúne as três raças, branca, negra e amarela, predomina [...]. A 
tendência à degenerescência é tão acentuada aqui quanto poderia ser num povo decadente e esgotado. A propensão às doenças mentais, às afecções graves do sistema nervoso, à degenerescência física e psíquica é das mais acentuadas.

A saber, esse tipo de discurso científico consolidou-se nas instituições da Primeira República, criando uma maior desigualdade social e política na população brasileira. Os pobres, negros e mestiços que não trabalhavam, que jogavam capoeira, que professavam religião de matriz africana eram criminalizados, presos ou diagnosticados como loucos e depositados em hospícios, a fim de serem retirados do convívio social. Assim, ao longo da história, a discriminação foi institucionalizada tanto por discursos normativo-legais quanto científicos. Desse modo, quando um jovem negro se insurgia contra a discriminação e sua condição social, corria o risco de ser criminalizado ou encerrado em um hospício, pela taxionomia do discurso científico que institucionalizou o conceito de raça disseminado na sociedade brasileira.

Conforme escreveu Lima Barreto, através da fala de um personagem que difundia esses discursos raciais, no conto "Dentes negros, cabelos azuis" (2011): "Posso lhe afirmar que é um degenerado, um inferior, as modificações que ele apresenta correspondem a diferenças bastardas, desprezíveis de estrutura física; vinte mil sábios alemães, ingleses, belgas, afirmam e sustentam" (BARRETO, 2011, p. 262).

Lima Barreto era esse jovem negro que a cada texto insurgia-se contra o racismo nas instituições e nas relações sociais no Brasil. Por conta disso, não escapou desse tipo de diagnóstico, tendo sido internado duas vezes no Hospício Nacional de Alienados, em 1914 e em 1920. Suas internações são relatadas em contos a exemplo de "Como o homem chegou" (2011), sobre sua primeira internação forçada, e nos textos Diário do Hospício e Cemitério dos Vivos (2015), romance inacabado, a partir da segunda internação. Após a saída em 1914, Lima Barreto satiriza o comportamento dos chamados doutores em seu conto "Teorias do Doutor Caruru":

Dr. Caruru era uma sumidade em matéria de psiquiatria, criminologia, medicina legal e outras coisas divertidas. Tinha, na nossa democracia, por ser sumidade e doutor, direito a exercer quatro empregos. Era lente da Escola de Medicina, era chefe do Gabinete Médico da Polícia, era subdiretor do Manicômio Nacional e também inspetor da Higiene Pública. Caruru tinha mesmo publicado várias obras, entre as quais se destacavam Os caracteres somáticos da degenerescência - livro que fora muito gabado pelo estilo saborosamente clássico (BARRETO, 2011, p. 413). 
Contra esses discursos, Lima Barreto insurgiu-se, em trecho escrito em seu Diário Íntimo: “A capacidade mental dos negros é discutida a priori, a dos brancos a posteriori. A ciência é um preconceito grego, é ideologia" (BARRETO, 1998, p. 15).

Foi a partir dessa mentalidade da discriminação racial que a passagem do século XIX para o XX configurou extrema violência do Estado brasileiro contra negros e afrodescendentes, seja no massacre de sertanejos mestiços em Canudos (1857); seja nas ruas da capital do Rio de Janeiro; seja através das práticas remanescentes da escravidão como a continuidade das chibatas contra os marinheiros negros, quando João Cândido, chamado o almirante negro, revoltou-se, assumiu um navio, apontou seus canhões para edifícios das instituições da Primeira República, aconteceu a Revolta da Chibata (1910). Preso, João Cândido foi prontamente internado em um hospício e expulso da marinha.

Histórias como a de Lima Barreto, João Cândido e dos mortos em Canudos não foram esquecidas, embora a versão divulgada tenha sido escrita pelas instituições da República Velha. A literatura de Lima Barreto, em sua época, foi contestada por críticos como José Veríssimo (2001), que escreveu: "o quadro saiu-lhe acanhado e defeituosamente composto, e a representação sem serenidade, personalíssima"; já críticos posteriores, como Antônio Candido, percebiam que a literatura de Lima Barreto era viva e penetrante, voltada para o desmascaramento da sociedade e a análise das próprias emoções. Mas, segundo Candido (1997, p. 549), Lima Barreto era "um narrador menos realizado, sacudido entre altos e baixos, frequentemente incapaz de transformar o sentimento e a ideia em algo propriamente criativo". Os mortos de Canudos tiveram sua história oficializada nos relatos de Euclides da Cunha, militar que se apropriou de uma abordagem positivista e evolucionista para caracterizar os sertanejos. Conforme o autor de Os sertões:

A mistura de raças mui diversas é, na maioria dos casos, prejudicial. Ante as conclusões do evolucionismo, ainda quando reaja sobre o produto o influxo de uma raça superior, despontam vivíssimos estigmas da inferior. A mestiçagem é um retrocesso. Como nas somas algébricas, as qualidades dos elementos que se justapõem não se acrescentam; subtraem-se ou destroem-se segundo caracteres positivos e negativos em presença. E o mestiço - mulato, mameluco ou cafuzo - menos que um intermediário é um decaído, sem a energia física dos antecedentes selvagens, sem a altitude intelectual dos ancestrais superiores. Contrastando com a fecundidade que acaso possua, ele revela casos de hibridez moral extraordinários: espíritos fulgurantes, às vezes, mas frágeis, irrequietos, inconstantes, deslumbrando um momento e extinguindo-se prestes, feridos pela fatalidade das leis biológicas, chumbados ao plano inferior da raça menos favorecida (CUNHA, 1984, p. 87). 
Lima Barreto viveu esse Brasil em que a mentalidade escravocrata persistia, perpetuando relações senhoriais, a fim de naturalizar a divisão racial e tentar apagar a história da participação da cultura do povo negro e afrodescendente considerados inferiores e incivilizados. A maior parte da população negra encontrou-se marginalizada dos direitos mais básicos, sendo alvo dos discursos raciais de caráter científico, cuja colonização não se daria tão somente sobre os corpos, mas também sobre o espírito e as mentes de todos os brasileiros.

Não podemos esquecer o passado. As histórias de sofrimento e luta da população negra e afrodescendente brasileira reclamam narração. Histórias como a de Lima Barreto, João Cândido, dos mortos em Canudos, entre outras, demoraram para serem recontadas de maneira diferente daquela escrita pela versão institucionalizada. A partir do recontar as histórias, pode-se compreender que a versão dita pelos vencedores não corresponde ao passado. As experiências e a vida dos negros e afrodescendentes no Brasil necessitam ser recontadas e ganhar sentido para os jovens. Desse modo, narrativas como as da literatura de Lima Barreto encontram-se permeadas de reconciliação, aproximando as gerações mais novas do passado de seus ancestrais.

\section{Reconciliação, ancestralidade, memória}

Ao buscar a reconciliação com o passado e encontrar a história dos seus ancestrais, Lima Barreto escreve, em 1909, seu primeiro romance, Vida e Morte de M. J. Gonzaga de Sá, que só veio a ser publicado em 1919. Conta a história do jovem negro Augusto Machado, que reivindica para si uma forma de viver no mundo permeado de preconceitos: "Sonho também por minha conta, ao jeito dos meus mortos; e os meus sonhos são mais belos porque são imponderáveis e fugazes" (BARRETO, 1919, p. 24).

A criação literária barretiana está impregnada do diálogo com um passado que estava sob os escombros da ideia de progresso: seja na modernização da cidade do Rio de Janeiro, que deliberadamente apagava a história, renomeava a geografia natural de antigos morros, destruía a antiga arquitetura para a construção de grandes avenidas para automóveis; seja na exclusão social de trabalhadores e negros; seja na violência de Estado contra manifestações afro-brasileiras. No conto "O moleque", que faz parte do livro Histórias e Sonhos (2008), publicado em 1920, Barreto escreveu:

Inhaúma é ainda dos poucos lugares da cidade que conserva o seu primitivo nome caboclo, zombando dos esforços dos nossos edis para apagá-lo. É um 
subúrbio de gente pobre [...]. Fogem para lá, sobretudo para seus morros e escuros arredores, aqueles que ainda querem cultivar a Divindade como seus avós. Nas suas redondezas, é o lugar das macumbas, das práticas de feitiçaria com que a teologia da polícia implica, pois não pode admitir nas nossas almas depósitos de crenças ancestrais. [...] O padre, para o grosso do povo, não se comunica no mal com ela; mas o médium, o feiticeiro, o macumbeiro, se não a recebem nos seus transes, recebem, entretanto, almas e espíritos que, por já não serem mais da terra, estão mais perto de Deus e participam um pouco da sua eterna e imensa sabedoria (BARRETO, 2008, p. 16, grifo nosso).

A memória está nas práticas religiosas, nas experiências presentes nas histórias dos antepassados, que transcendem uma geração antiga ao serem transmitidas para novas gerações. A vida daqueles que construíram esse mundo não se finda com a morte. "Ao jeito dos meus mortos", como afirma Lima Barreto de maneira muito particular ao expressar a condição de existência da gente do subúrbio, em sua maioria, negros e mestiços. A literatura de Barreto se encontra na arte de narrar histórias de sobrevivência da memória dos antepassados nas agruras vivenciadas pelos seus descendentes vivos. Lima Barreto é um dos primeiros escritores brasileiros a chamar a presença da ancestralidade, a convivência com os antepassados, os seus mortos. Segundo Eduardo Oliveira (2007, p. 245),

Ancestralidade é como um tecido produzido no tear africano: na trama do tear está o horizonte do espaço; na urdidura do tecido está a verticalidade do tempo. Entrelaçando-se os fios do tempo e do espaço cria-se o tecido do mundo que articula a trama e a urdidura da existência. A ancestralidade é um tempo difuso e um espaço diluído. Evanescente, contêm dobras, labirintos se desdobram no seu interior e os corredores se abrem para o grande vão da memória. A memória é precisamente os fios que compõem a estampa da existência.

As narrativas carregam espíritos, ecoam vozes, memórias e experiências dos antepassados. Segundo Vanda Machado (2004), “A compreensão de nós mesmos e do lugar onde celebramos a ancestralidade renova a vida de velhos e novos". A ancestralidade transcende a existência de uma única geração, com ela cria-se uma temporalidade singular em que uma geração passada se encontra com uma mais nova. Essa é umas das formas de transcender o tempo da vida através da arte da narrativa de histórias, ficcionais ou não.

As histórias consubstanciam um processo de resistência constituído no fortalecimento de uma tradição. A escrita literária de Lima Barreto insurgiu-se contra o apagamento de diversas histórias pela violência do Estado. Essas histórias vivenciadas por pessoas do subúrbio, principalmente negras, cujos antepassados forçadamente vieram da África para serem escravizados no Brasil, ainda não haviam encontrado sua efetiva liberdade, mesmo após a abolição da escravatura. Embora à margem da sociedade, essas histórias sobreviveram 
e permanecem vivas na memória de muitos, eram experiências antigas, culturais e religiosas, que não foram retiradas do convívio ante a resistência para que continuassem a ser transmitidas às futuras gerações.

O conhecimento da história comum em busca de um sentimento identitário perpassa a memória, que transmite a cultura, a religiosidade, os costumes na sobrevivência de cada dia. Conforme lembra Vanda Machado (2006, p. 81), “A memória mantém uma revivência que não é tal como já aconteceu, mas como vem se repetindo nas suas diferenças em tempos e lugares. Neste contexto, a memória, que não separa o presente do passado, vai além atualizando os fatos da vida e da história”. Na memória também é possível encontrar o sacrifício dos antigos, não para repetir suas lutas, mas para aprender com elas e, assim, encontrar novas formas de lutar, para que um passado de preconceito não venha a se repetir.

Apesar da violência do Estado que tentou apagar essa origem cultural da memória dos afrodescendentes, essa tradição ancestral sobreviveu através da cultura, da religiosidade e das experiências cotidianas: nos diálogos, nos alimentos, nas manifestações culturais e religiosas, nos ditados populares, conselhos que os novos recebem dos mais velhos, etc. Uma forma de vida antiga que se manifesta no espetáculo das águas, dos céus, das casas, das gentes, do pedaço da terra em que os antepassados nasceram e viveram.

A ancestralidade é o encontro com as experiências dos mortos, aqueles que construíram e lutaram por seus direitos e pelos direitos de seus filhos nesse mundo. Os mortos fazem-se presentes na existência de cada um e na construção da realidade social e histórica brasileira. Os vivos precisam compreender os sacrifícios dos mortos, pois o passado pode revelar-se no presente. Do mesmo modo, os mortos ainda merecem o reconhecimento dos vivos, presente no sacrifício que os vivos fazem, com vistas à continuidade da luta que os mortos empreenderam. O legado de histórias e experiências dos mortos surge enquanto oferendas, nas quais os vivos podem agradecer pelos ensinamentos de seus antepassados, e, assim, pensar o futuro.

\section{Educação, narrativas e futuras gerações}

Mesmo com a inclusão da temática "História e Cultura Afro-Brasileira" nos currículos oficiais, através da Lei $\mathrm{n}^{\circ} 10.639 / 2003$, o educador ainda carece refletir quanto às práticas didáticas sobre a cultura e a história afro-brasileira. Conforme as Orientações e Ações para a Educação das Relações Étnico-Raciais, "Reconhecer as diferenças é um passo fundamental para a promoção da igualdade, sem a qual a diferença poderá vir a se transformar em 
desigualdade" (BRASIL, p. 32, 2006). Desse modo, a reflexão étnico-racial sobre a cultura afro-brasileira constitui-se de modo dialético para a compreensão de prática didática para o educador, assim como na aprendizagem das crianças.

A educação sem pertencimento, sem compreensão da existência da história, sem reconhecimento da luta das gerações anteriores, apresenta-se como modelo no qual não se pensa a política, nem a ação, nem a liberdade. Nesse panorama de desamparo, aqueles que governam por meio da força manipulam as leis e tendem a reformar a educação em atenção aos interesses privados, não aos públicos. Assim, essas ações de Estado sobre a educação anulam a capacidade de compreender o mundo e a potencialidade da liberdade, de agir e do surgimento de um novo começo, o que afasta a potência significativa da educação, que se dá pelo cuidado com o acolhimento das crianças e dos jovens na apresentação do passado.

A reconciliação não é aceitar resignadamente a imprevisibilidade, mas compreender que todo acontecimento no mundo humano carece de um sentido. As experiências humanas, contadas pelos professores aos estudantes, geração em acolhimento, cortam o tempo entre as gerações.

Definitivamente, tal concepção de educação perpetua os resquícios de uma sociedade elitista, como se constituiu historicamente a sociedade brasileira. Ter o direito a qualquer direito prescrevia uma situação de privilégios. Na passagem do século XIX ao século XX, por exemplo, o Estado brasileiro negligenciou a educação para mulheres e homens, em sua maioria de origem negra, outrora escravizados, agora ditos "livres", marginalizados na cidade. Considerados cidadãos de segunda categoria, não podiam votar, devido à legislação, em virtude do analfabetismo. Sem o acesso à educação escolar, sem possibilidade de efetivar a voz e a ação sobre o mundo, as pessoas negras ainda hoje lutam por direitos. Segundo Albuquerque e Fraga (2006, p. 197), no livro Uma história do negro no Brasil:

Para os ex-escravos e para as demais camadas da população negra, a abolição não representou apenas o fim do cativeiro. Para eles a abolição deveria ter como consequência também o acesso à terra, à educação e aos mesmos direitos de cidadania que gozava a população branca. Na ausência de qualquer iniciativa séria por parte do governo para garantir um futuro digno aos negros brasileiros após o dia 13 de maio, um grupo de libertos da região de Vassouras, no Rio de Janeiro, endereçou uma carta a Rui Barbosa, então figura importante da política nacional. Na carta, eles reivindicavam que os filhos dos libertos tivessem acesso à educação.

A narrativa do escritor brasileiro Lima Barreto no conto "O Moleque" (2008) demonstra, de modo contundente, os efeitos da ausência da educação para a população negra, na realidade da construção política e social brasileira. Nesse contexto, o enredo da estória de 
Lima Barreto mostra como, após séculos de escravidão no Brasil, um dos últimos países do Ocidente a abolir o regime escravocrata, consolidou-se o processo de marginalização da maior parte da população negra, alijada dos direitos fundamentais, entre os quais a educação. Lima Barreto conta a estória de uma mulher negra, entre muitas, que cria seu filho sozinha, lavando roupa. Escreve Lima Barreto (2008, p. 25):

\begin{abstract}
A mãe tinha vontade de pô-lo no colégio; ela sentia a necessidade disso todas as vezes que era obrigada a somar os róis. Não sabendo ler, escrever e contar, tinha que pedir a "seu" Frederico, aquele "branco" que fora colega de seu marido. Mas, pondo-o no colégio, quem havia de levar-lhe e trazer-lhe a roupa?
\end{abstract}

O preconceito tem cor, classe social e gênero. Na República brasileira, a exclusão do acesso à educação escolar ainda é uma das piores faces da sociedade. Na dicotomia social e política, ao longo da história brasileira, trabalha para sobreviver e só estuda aquele que tem condições materiais. A existência de exceções é caracterizada pelo mérito individual de cada um. Nessa perspectiva excludente, a educação salvaria homens e mulheres pobres e negros do inexorável destino que a eles está condicionado. Um engano, porque, atualmente, o braço armado do estado brasileiro adentra comunidades da periferia e favelas no Brasil, com alegação de "pacificação"; invade escolas com armas de grosso calibre; aborda e revista estudantes, crianças e jovens, e suas mães, após um dia de aula, no trajeto de casa.

Ações de Estado banalizam a violência no cotidiano das novas gerações; normalizam a ideia de que essas crianças, pobres e negras, presas fáceis, quando adultas, sejam jogadas no sistema carcerário e burocrático da justiça, tratadas como delinquentes, ou destinadas a trabalhos que não têm seu reconhecimento merecido, como domésticas e serviços gerais sujeitos atacados por setores da elite, quando têm minimamente reconhecidos seus direitos. Tal visão de mundo pauta-se em uma lógica argumentativa perversa, com a qual as crianças e os jovens devem lidar diariamente, pois o Estado os trata desde cedo como uma ameaça ao patrimônio daqueles que não vivem em comunidades de periferia.

Os jovens possuem alguma maturidade para compreender os acontecimentos do mundo que os cerca, pois desde cedo fazem parte de uma sociedade excludente com preconceitos e discriminação. Nesse sentido, através da educação, que tem como potência a conservação do legado cultural, a escola não pode deixar de contar as estórias das gerações passadas. A escola deve ser um espaço de compartilhamento entre os diferentes para que os estudantes possam conhecer e assim compreender o mundo do qual fazem parte. A escola pode favorecer a superação do preconceito, na medida em que discute questões como a 
discriminação devido às diferenças entre as pessoas: cor de sua pele, condição física, gênero, sexualidade, religião, cultura etc. Assim, a educação objetiva o reconhecimento de que todos ocupam o mesmo mundo, que é comum, e queos jovens precisam compreender, para com ele se reconciliar.

\section{Considerações finais}

A literatura de Lima Barreto é esse ato de resistência, de reconciliação com o passado; de luta na busca não de uma identidade nacional, mas de "cultivar a divindade como seus avós” (BARRETO, 2008). Essa divindade ancestral, ente a ser lembrado pelas novas gerações, constitui-se no reencontro com a tradição brasileira.

Assim, a reconciliação dos jovens com a tradição é possibilitada ao penetrar na história do Brasil, nas histórias dos sujeitos que foram marginalizados, ao encontrar os afetos, as vidas e as experiências destruídas desde o processo de colonização até os dias atuais. A reconciliação com a tradição constitui-se na ancestralidade reavivada pela memória dos antigos da cultura afro-brasileira, cuja presença na história do Brasil deve engendrar-se em cada nova geração. Portanto, deve-se ler Lima Barreto não apenas para conhecer essa história, mas para reconhecer-se nela e encontrar o encantamento com o passado.

\section{Referências}

ALBUQUERQUE, W. R.; FRAGA, W. Uma história do negro no Brasil. Salvador: Centro de Estudos Afro-Orientais; Brasília: Fundação Cultural Palmares, 2006.

BARBOSA, F. A. A vida de Lima Barreto. 8. ed. Rio de Janeiro: José Olympio, 2002.

BARRETO, L. Vida e Morte de M. J. de Sá Gonzaga. Revista do Brasil. São Paulo, 1919. . Os Bruzundangas. São Paulo: Ática, 2012.

\footnotetext{
Diário Íntimo.

1956.

Link:

http://www.dominiopublico.gov.br/pesquisa/DetalheObraForm.do?select_action=\&co_obra=2 078. Acesso: 01 de Março de 2018. Histórias e Sonhos. São Paulo: Martins Fontes, 2008.

Contos Completos de Lima Barreto (org. Lilia Moritz Schwarcz). Rio de Janeiro: Companhia da Letras, 2011.

Triste Fim de Policarpo Quaresma. 24ª edição. São Paulo: Ática, 2010. Recordações do Escrivão Isaías Caminha. São Paulo: Ática, 1997.

. Um longo sonho de futuro: diários, cartas, entrevistas e confissões dispersas. Rio de Janeiro: Graphia, 1998.

BRASIL. Ministério da Educação. Orientações e Ações para a Educação das Relações Étnico-Raciais. Brasília: SECAD, 2006. Disponível em: <http://portal.mec.gov.br/dmdocuments/orientacoes_etnicoraciais.pdf> Acesso: 02 de abril de 2018.
} 
CÂNDIDO, A. Os olhos, a barca e o espelho. In: HOUAISS, Antônio e Figueiredo, Carmem Lúcia Negreiros de (Org.). Lima Barreto - Triste fim de Policarpo Quaresma (Edição crítica). Madri: Coleção Archivos/Scipione Cultural, 1997.

CUNHA, E. Os sertões. São Paulo: Círculo do Livro,1984.

LACERDA, J. B. The Metis, or half-breeds, of Brazil. Link: http://etnolinguistica.wdfiles.com/local--files/biblio\%3Alacerda-1911metis/lacerda_1911_metis.pdf Acesso: 01 de Março de 2018.

MACHADO, V. Tradição oral e vida africano, afro-brasileira. In: SOUZA, Forentina; LIMA, M. N. Literatura Afrobrasileira. Salvador: Centro de Estudos Afro-Orientais; Brasília: Fundação Cultural Palmares, 2006.

MACHADO, V.; PETROVICH, C. Irê Ayó: Mitos Afro-brasileiros. Salvador: EDUFBA, 2004.

OLIVEIRA, E. Filosofia da ancestralidade: corpo e mito na filosofia da educação brasileira. Curitiba: Editora Gráfica Popular, 2007.

RODRIGUES, N. (1899). Mestiçagem, degenerescência e crime. Hist. cienc. Saúde Manguinhos [online], v.15, n. 4, p. 1151-1180, 2008. ISSN 0104-5970.

SCHWARCZ, L. M. Lima Barreto: triste visionário. 1a ed. São Paulo: Companhia das Letras, 2017.

VERÍSSIMO, J. “Lima Barreto”. In: BARRETO, Lima. Prosa seleta. Rio de Janeiro: Editora Nova Aguilar, 2001. 